\title{
Meaning and Thematic Roles in the Igbo Language
}

\author{
Chukwuma O. Okeke*
}

\section{Abstract}

Semantics is an aspect of linguistic study that investigates the meaning of words and sentences in languages. Scholars from different disciplines like philosophy, logic, anthropology, psychology and linguistics are interested in exploring the nature of meaning. But linguistics differs from these disciplines because it investigates meaning in a systematic and objective pattern. As people's experiences and world view change, so do the meanings they associate to word change. Therefore, meaning is a concept usually influenced by different factors. An utterance can be interpreted in diverse ways depending on the emotional disposition of the speaker at the time of making the utterance. Because of this, the intended meaning of an utterance may be different from the meaning perceived by the receiver of the message. By adopting the thematic approach to the study of meaning, this paper x-rays the different dimension of meaning with special emphasis on the investigation of theta roles in the Igbo language. The paper argues that as part of its inherent lexical specification, a verb or a preposition requires its arguments (which are usually nouns) to be in specific thematic roles because where there is one argument, there is one theta function; and the semantic interpretation of a particular object is the determining factor for the type of theta role the argument will be assigned.

http://dx.doi.org/10.4314/ujah.v13i2.9

\section{Introduction}

Etymologically, according to Ndimele (1997), the word semantics (from French semantique) was "invented" by Michel Bréal in the $19^{\text {th }}$ century. In Linguistics, semantics is the subfield devoted to the study of meaning, as borne at the 
syntactic level of words, phrases, sentences, and even larger units of discourse (referred to as texts). As with any empirical science, semantics involves the interplay of concrete data with theoretical concepts. In semantics, explicit ways in which words and sentences of various grammatical constructions are used and understood by fluent speakers of a given language are investigated.

Semantics is an area of linguistics which studies the meaning of words and sentences in languages. Although Ndimele (1997) avers that the term appeared in Bréal's book, Semantics: Studies in the Sciences of Meaning, it took time before the term gained wide currency. It came into popular use about the first half of the $20^{\text {th }}$ century. But this does not suggest that the study of meaning is as recent as that. Since the time of Plato and Aristotle, scholars have been interested in investigating the nature of meaning. Scholars from philosophy, logic, psychology, anthropology, and recently linguistics have paid great attention to the study of the nature of meaning, (Ndimele, 1997). Linguistics, however, differs from these other disciplines in the sense that it studies meaning in a systematic and objective way. The meaning may relate to the meaning of word or words in combination. Meanings are not necessarily determined by words, but the people who use the words. As people's experiences and world view change, so the meanings they associate with words change.

\section{The Nature of Meaning}

Semantics has been defined as a level of linguistics which studies meaning. A most puzzling question looks simple when first encountered, but the fact is that no linguist has been able to provide a precise and accurate definition of meaning. For over 2,000 years scholars have made attempts to define meaning without much success. Today, there is no universally accepted definition of meaning. The problem with the word, meaning, is that it serves several functions. It has many 
meanings itself. For instance, people are often heard using the following words or phrases to refer to what something means: "stands for", "signifies", "denotes", "symbolizes", means", "implies", "translates as", "represents", “expresses", "portrays", designates", "indicates", etc. The fact which emerges from the above discussion is "... meaning is a harlot among words; a temptress who can seduce the writer or speaker from the path of intellectual chastity", (Cherry 1957: 112).

Meaning is a phenomenon that can be influenced by different variables. One stretch of utterance can mean different things to different people depending on their background or emotional disposition at the time the utterance is rendered. This is why the intended meaning of an utterance may be different from the meaning perceived by the receiver of the message.

In an attempt to account for the meaning of meaning, C. K. Ogden and I. A. Richards, in their monumental book entitled The Meaning of Meaning (1923), present twenty-two different definitions of meaning. The lesson which could be deduced from these definitions is that no precise and satisfactory answer can be given to the question, "what is meaning"? This apparent lack of a satisfactory answer has made some scholars skeptical about semantics as a legitimate field of study. A second conception of the nature of meaning which is often referred to as the conventionalist view is largely traceable to the words of Aristotle. Proponents of this view are of the opinion that the connection between sound and meaning is arbitrary and never direct.

\section{Theories of Meaning}

One of the major problems facing linguistics has been how to define meaning. In an attempt to provide a solution to the meaning of meaning, which some scholars are concerned 
about, a number of theories of meaning have been formulated. They are as follows:

\section{a. The Referential Theory of Meaning}

The proponents of this theory are C. K. Ogden and I. A. Richards (1923). According to them, the meaning of an expression is the actual entity in the real world to which it refers. In other words, this theory is saying that a word means what it refers to. This actual object is referred to as the referent. The connection between a linguistic unit and its referent is only possible through thought and it also denies a direct link between expressions and their referent. Ogden and Richards, in Ndimele (1997: 17), illustrate this theory using what they called a semiotic triangle.

Referent

Thought

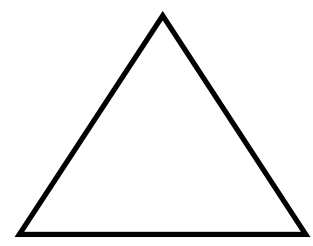

Symbol

The above triangle distinguishes three different components of meaning and emphasizes that a non-direct link exists between a linguistic unit (symbol) and the entity (referent) to which the symbol refers. Such a view of meaning can only be used to explain concrete nouns. Examples are: Chika, chair, goat, dog, pen, etc. The theory excludes sentences. It also excludes adjectives because they have no referent. It refers to a sub-set of possible nouns in any given language. The referential theory can extend to sentences by saying that the meaning of an expression $\mathbf{E}$ is its referent. That is, only sentences that have referent can have meaning. Examples: 
1. Hausa man studying Hausa or

2. He is studying Hausa

The above sentences have no referent. Therefore, they mean that a referent and meaning are not necessarily synonymous. The theory of meaning permits us to make the following claims:

a) If an expression $\mathbf{E}$ has a meaning, it must have a referent.

b) If two expressions have the same referent, then they must have the same meaning. Each of these two claims of the theory is false.

In (a), it says that every expression must have a meaning with a referent. But this is false because many expressions in different languages have meaning but without referent. Example:

3. Today is Monday. This is a sentence that has meaning without a referent.

Also (b) claim is false. Example:

4. The first man to land on the moon was Major Yuri Gagarin. Here, we have two expressions with a common referent but different meanings, because they are not synonymous. Therefore, the referential theory is not reliable; it gives a partial account of meaning. Because the word - referent relationship is accidental; we cannot base the definition of meaning wholly on the referential theory.

\section{b. Mentalistic Theory of Meaning}

This is a refinement of the referential theory of meaning. Proponents of this theory view the meaning of a word or an expression as the mental image or idea of the word or expression that is formed in the mind of the speaker or hearer as soon as the word or expression is uttered. Scholars like 
Glucksberg, S. and J. Danks (1975) in Ndimele (1997:19) are strongly behind this theory as can be seen in the following quotation:

The set of possible meanings of any given word is the set of possible feelings, images, ideas, concept, thought and inferences that a person might produce when that word is heard and processed.

This expression can be restricted to this: the meaning of an expression $\mathbf{E}$ is the idea or ideas associated with $\mathbf{E}$ in the mind of the people. This theory is vague and not amenable to testing because a theory is strong depending on its verification and falsity.

\section{c. Use Theory of Meaning}

According to Ndimele (1997: 20), a German scholar, Wittgenstein, in his book entitled Philosophical Investigations, proposed this theory as an alternative to the previous theories. To him, the meaning of any linguistic expression (be it a word, a phrase or a sentence) is determined by the context in which it is used. The meaning of an expression, therefore, is the effect (or effects) that it creates in a particular context in which the expression is used. So, for one to know the meaning of a word, one has to listen and see how it is used by speakers of that language. This theory of meaning does not suffer from the defects of the previous theories. The unfortunate thing about this theory is that the study of language use belongs to pragmatics, and we cannot approach meaning through pragmatics.

\section{d. Componential Analysis (CA)}

The earliest proponents of this theory are L. Hyemslev, R. Jakobson and F. Glounsbury. This theory assumes that words are made of units of meaning known as components. These 
components are largely inherent features of meaning. Example: in the analysis of a noun, it may be concrete or abstract, countable or mass, human or non-human, male or female, proper or common. The features associated with nouns appear in pairs of opposites. The CA has a binary notation: \pm Example:

$$
\begin{aligned}
& \text { mother } \\
& \text { + Noun } \\
& \text { + Human } \\
& \text { + Female } \\
& \text { + Adult } \\
& \text { + Countable } \\
& \text { + Parent }
\end{aligned}
$$

$$
\begin{aligned}
& \text { father } \\
& \text { + Noun } \\
& \text { + Human } \\
& \text { - Female } \\
& \text { + Adult } \\
& \text { + Countable } \\
& \text { + Parent }
\end{aligned}
$$

Even though CA can be used to characterize concrete nouns, it fails as a way of characterizing abstract nouns because the meaning of any vocabulary item appears too complex to be handled in terms of binary notations. It definitely fails as a model for characterizing verbs. Therefore, the economy involved in the simple way of notation is very attractive but very deceptive. If the system is to be applied to the description of meaning, it must be made more complex than a mere bi-partite notation.

\section{Dimensions of Meaning}

Although the different shades of meaning are multifarious, linguists have found it fairly convenient to discuss the several types of meaning under three broad classes. They are: the conceptual, associative and thematic meaning.

\section{a. Conceptual Meaning}

The conceptual meaning according to Ndimele (1997: 32) is sometimes referred to as the denotative, cognitive, logical, central or primary meaning of a word. It is the ordinary basic 
dictionary meaning of a word which is normally stable and not affected by contextual colouring or emotional overtones of either the speaker or the hearer. Here, all the speakers of one language share a common conceptual meaning of lexical items; hence this type of meaning has a universal implication. The conceptual meaning of a word can be expressed in terms of contrastive semantic features. For example, the meaning of boy can be contrasted with the meaning of girl as follows:

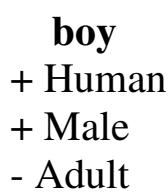

$$
\begin{gathered}
\text { girl } \\
+ \text { Human } \\
\text { - Male } \\
\text { - Adult }
\end{gathered}
$$

The semantic features which are used in specifying the conceptual meaning of lexical items are contrastive in the sense that if a semantic feature for a particular word is plus (+), it cannot at the same time be minus (-), Ndimele (1997).

\section{b. Associative Meaning}

Associative meaning is that type of meaning which a word conveys over and above its ordinary basic or commonly shared sense. It is unstable, open-ended and variable in nature. Associative meaning can be influenced by sex, the experience of the speaker or hearer, the historical epoch in which the word is used, the society or the culture, (Ndimele 1997 and Saeed 1997).

At times an individual may use a particular word in such a way as to arouse emotional response in someone who uses the same language. This may be due to the idea which the word communicates, the context with which the word is associated, or what the word conveys to the hearer about the attitude or behaviour of the speaker, (Barnwell 1980).

Barnwell (1980) and Leech (1981) recognize five subclasses of associative meaning. They are connotative meaning 
(a type which an expression has by virtue of what it refers to, over and above its purely conceptual content). Collocative meaning according to Crystal, (1997) is used to refer to the habitual co-occurrence of individual lexical items; affective meaning (when words are chosen in a particular manner to communicate something about the attitude or feeling of the speaker towards his hearer or the subject-matter of discourse); reflected meaning (situations where an expression has more than one conceptual meaning); and stylistic or social meaning (a type of meaning which a word conveys due to the fact that it is associated with a particular pattern of speech, a language variety or a social setting).

\section{c. Thematic Meaning}

This is the type of meaning which an expression conveys depending on how the speaker organizes his message in terms of focus and emphasis, (Leech 1981). In certain situations, a speaker may decide to make one part of the sentence communicatively prominent over and above other surrounding words in the same sentence. The different ways of achieving communicative prominence in a sentence are through focalization, topicalization and passivization or through the use of certain prosodic features such as stress and intonation. Compare the following pairs of sentences:

(5) James killed the fowl vs. The fowl was killed by James.

(6) Obi slapped his wife vs. It was Obi who slapped his wife.

The first sentence in each of the pairs above is neutral in terms of emphasis. It is in the second sentence that we find a word or phrase that is emphasized. 


\section{Thematic Meaning in Igbo}

Linguists, from Gildea's (2002) analysis, use theta roles to explain the interface between semantics and syntax: specifically to characterize the link between semantic classification inherent in a verb meaning and the grammatical relations it supports. The following role assigners are present in Igbo:

i. Anaphora: In anaphora, nouns assign reference to pronouns, that is, antecedent - anaphor relations.

ii. Verbs assign roles to arguments, (arguments are usually nouns and pronouns). See (7).

[In the Igbo data here the following abbreviations are used; PAST - past tense, AUX - auxiliary, APP - applicative, VP vowel prefix, OVS - open vowel prefix]

(7) Chuma gburu ewu

Chuma kill-PAST goat

'Chuma killed goat'

iii. Prepositions assigning roles to arguments. The roles here are indirect because the verb comes between the prepositions and the argument. Example:

(8) Chuma kwuru gbasara Okeke

Chuma talk-PAST shoot.affect Okeke 'Chuma talked about Okeke'

In this paper, the Igbo theta role will be analyzed using the principles of the theta criterion. The principles state that each theta role has a particular theta function; experiencer for instance cannot be a goal or a theme at a particular material time. If any clash occurs in theta function, the prominent one 
dominates the less one. The study of thematic functions is as follows:

\section{a. Agent}

An agent is the entity that deliberately performs the action. In other words, it is the entity that instigates an action or the movement of the theme. Napoli (1996) says that one quality of an agent is the ability to carry its function voluntarily. Example:

(9) Obi mara Ada ura.

Obi throw-PAST Ada slap

'Obi slapped Ada'

In the above example, Obi has the theta role of the agent; whereas Ada has the role of the patient. This is because the action of the agent - Obi affects the patient, Ada. In other words, Obi can control his action on Ada by deciding not to slap her but cannot resist to be slapped by Obi. Obi's action on Ada is voluntary.

(10) Emeka jere ahịa

Emeka go-PAST market

'Emeka went to the market'

In sentence (10) above, Emeka is the agent. Emeka is the agent here because his going to the market is volitional and under his control. In other words, Emeka might decide not to go the market.

\section{b. Patient}

The patient is the entity that undergoes the action and has its state changed. A patient must not just be animate but it must be a human. Here, the action is direct because nothing comes between the verbs and the arguments. Example: 
(11) Amaka kụrụ di ya ihe Amaka hit-PAST husband her something 'Amaka hit her husband'

In the above sentence, $\boldsymbol{d i}$ has the theta role of the patient. It receives the effect of the action of Amaka. Amaka on her own has the theta role of hitting the husband.
(12) Isi na-awa
Nwaafọ
Head AUX-VP-break Nwaafọ
'Nwaafọ has a headache'

The above example portrays Nwaafq as the sufferer of the effect of the headache. Therefore, Nwaafq is the patient and/or experiencer of the sentence while isi qwxwa is the instrument.

(13) Oyi tụrụ

nwa m

Cold throw-PAST child I

'My child had a cold'

In example (13) above, $\boldsymbol{n w a} \boldsymbol{m}$ has the theta role of patient and/or experiencer while cold has the theta role of force because it is an unconscious participant which is causal and cannot be manipulated.

\section{c. Experiencer}

The experiencer receives sensory or emotional input. In other words, this role is performed by the entity that undergoes some psychological state. The experiencer may or may not be a human being but a patient must not just be animate but a human. This characteristic differentiates an experiencer from a patient. Example: 
(14) Emeka bara nsi

Emeka defecate-PAST faeces

'Emeka defecated'

(15) $\mathrm{O}$ were iwe

$\mathrm{He} /$ she anger-PAST anger

'He/she was angry'

"Emeka" in (14) and "O" in (15) are the entities that underwent some emotional or sensory input. The experiencers in those sentences have the ability not to engage in any of the psychological effects we saw in the sentences. Emeka has the ability not to defecate; $\boldsymbol{O}$ (he/she) can determine not to be angry since anger can be controlled.

\section{d. Beneficiary}

This is the object for whose benefit the action occurs. Example:

(16) Ogechi nyere Obi nsusu

Ogechi give-PAST Obi kiss

'Ogechi gave Obi a kiss'

(17) Ngozi gaara

nne ya ahịa

Ngozi go-APP-PAST mother her market

'Ngozi went to the market for her mother'

"Obi" and "Nne ya" in (16) and (17) respectively are the beneficiaries. Their theta role is that of benefactive. In (16), Obi benefited from Ogechi. In (17), 'Nne' benefited from the help of 'Ngozi'. The above benefactive roles are the more pronounced in the sentences by the introduction of the preposition 'to' in the translation of the sentence. 


\section{e. Instrument}

This is the entity used to carry out the action, Comrie (1989) defines instrument as a means used by the agent to carry out an action. Example:

(18) Ada jiri mma gbuo di ya Ada use-PAST knife kill husband her

'Ada killed her husband with a knife'

(19) Okoli jiri mbọ waa ọji

Okoli use-PAST nail break kolanut

'Okoli broke kolanut with his nail'

The above examples (18) - (19) are similar because of the occurrence of the verb "jiri", which depicts the theta role of the instrument in the sentence. "Mma" in (18) and mbọ in (19) are the instruments.

\section{f. Locative}

This is the entity where another may be found or where the action occurs. Locatives are usually introduced by a preposition or nouns incorporating a prepositional notion. Example:

(20) Ọgụ dị n’ugbo

Hoe be in farm

'The hoe is in the farm'

(21) Enyi kwụ ebe a

Enyi stand place this

'The elephant stands here'

In the above examples, "n'ugbo" and "ebe a" denote the location of the nouns. 


\section{g. Goal}

It is the location towards which the entity moves or where the action is directed towards. Whether the entity reaches the location or not is immaterial. Example:

(22) Obi si Enugu gaa Abuja

Obi from Enugu go-OVS Abuja

'Obi went to Abuja from Enugu'

(23) Ifeoma chọrọ ịbu akwụna

Ifeoma want-PAST to be harlot

'Ifeoma wants to become a harlot'

In sentence (22) above, "Abuja" is the goal and has the theta role of the goal of the agent. It is the termination point intended to be achieved. In (23), "to be a harlot" is the goal of Ifeoma. Her wish is to become a harlot. This is also the termination point intended to be achieved based on continual struggle. The mere mention of the statement is not what makes it a goal, but the marked desire that is backed with equal craving to achieve the result.

\section{h. Maleficiary}

This is the entity that suffers the action performed by the agent. Maleficiary and patient are different because maleficiary is indirect where patient is direct. Here, the action of the agent must be negative to the recipient. Example:

(24) Ọịa mebiri umi ọpụkpụ m

Sickness make.spoilPAST marrow bone me

'Sickness destroyed my bone marrow'

(25) Ifufe buuru moto nna ya

Wind carry-APP-PAST motor father him

'Wind carried his father's car' 
The arguments in the above examples "okpụkpu m" and "nna ya" are understood to be the entities on which the detriment of the destruction of bone marrow and taking of car took place. In (24), the reference of ' $m$ ' cannot walk very well as a result of the sickness, which affected his/her bone marrow. "Nna ya" in (25) is left without a car as a result of the activities of "ifufe". The actions of the agents in the sentences are all indirect and negative to affected entities. Hence, 'okpụkpụ m' and 'nna ya' are the maleficiaries of the above sentences.

\section{i. Motive}

It tells us why an action took place. It provides the reason why something happened; it is that propensity that propels somebody to act. Example:

\section{(26) Ibe lụrụ Amaka n'ihi na ọ hụrụ}

Ibe marry-PAST Amaka in reason that he see-PAST

ya n'anya

her in eye

'Ibe married Amaka because he loves her'

\section{(27) Ejima biri ego ka o wee zọọ ndụ}

Ejima borrow-PAST money that he take save life nna ya

father him

'Ejima borrowed money in order to save his father's life'

In example (26) above, the reason why 'Ibe' married is that he loves 'Amaka.' In (27), the motive for borrowing money is to save his father's life. In the above examples, the motive instigated the action and the reason is the physical manifestation of the motive. So, reason is usually cited as evidence from the previously set motive. 


\section{j. Force}

This is an unconscious participant which is causal and cannot be manipulated. Example:

(28) Ọụ gbara

ụlọ m

Fire burn-PAST house I

'Fire razed my house'

(29) Oyi tugburu onye nche anyi

Cold hit.kill-PAST watchman we

'Our watchman died of cold'

In examples (28-29), "okụ" and "oyi" possess the theta role of force. "Ụlọ" and "onye nche" are the direct objects of the action of the force.

\section{Summary of the Findings and Conclusion}

This paper has shown that Igbo, verbs and prepositions assign roles to arguments. Theta role assignment by the verb is direct while role assignment by the preposition is indirect. Also, thematic meaning is the only dimension of meaning in which a speaker organizes his messages in terms of ordering, emphasis and focus. The speaker may portray the roles (semantic role) and describe the relationship between these roles and grammatical relations.

This paper corroborates that the verb as part of its inherent lexical specification, requires its arguments to be in specific thematic role. This is reflected by its formulating thematic roles.

In conclusion, semantics universally is the study of meaning. It is assumed that there are certain basic facts which a basic semantic theory should account for: for instance, it should be able to account for both word and sentence meanings. It is a well known fact that all languages use both words and sentences in deriving meaning. So, every word or 
sentence is conventionally associated with at least one meaning. Therefore, for every language, the semantic theory must be able to assign to the word or sentence the meaning(s) associated with it in that language.

*Chukwuma Okeke is a lecturer in the Department of Linguistics, Igbo and Other Nigerian Languages, University of Nigeria, Nsukka 


\section{References}

Barnwell, K. Introduction to Semantics and Translation. Summer Institute of Linguistics. (1980).

Cherry, C. On Human Communication, Cambridge: MIT Press. (1957).

Comrie, B. Language Universality and Linguistic Typology. Oxford: Blackwell. (1989).

Crystal, D. A Dictionary of Linguistics and Phonetics, $4^{\text {th }}$ Edition. Oxford: Blackwell. (1997).

Gildea, G. "Probabilistic Models of Verb Argument Structures." In the Proceeding of the $17^{\text {th }}$ International Conference of Computational Linguistics. Milan: Italy. (2002).

Leech, G. Semantics. London: Penguin Books (1981).

Lorimor, L. T. (Ed.), The New Webster's Dictionary of the English Language. New York: Lexicon Publishers, 2000.

Mbefo, L. Coping with Nigeria's Two Fold Heritage. Enugu: Snaap Press, 1996.

Miller, D., "The Challenges of Poverty in a Globalized Economy". Paper Presented at One Day UNESCO Conference World Poverty and the Duty of Assistance, in Philosophy Now, Oct. 2006.

Ndimele, M. O. Semantics: The Frontiers of Communication. Port Harcourt: University of Port Harcourt Press Limited. (1997).

Ogden, C. K. and Richards, I. A. The Meaning of Meaning. London: Routledge and Kegan Paul Limited. (1923).

Peschke, K. Christian Ethics. Bangalore: St. Paul's Press, 1992. 
Ruch, E. A., Omi and Anyanwu, K. C. African Philosophy. Rome: Catholic Book Agency, 1981.

Saeed, J. I. Semantics, ( $2^{\text {nd }}$ edition), USA: Blackwell Publishing Company. (1997).

Spio-Garbrah, E., "Ghanaian Economy and Trade Protectionism". Paper Presented at one day UNESCO Conference World Poverty and the Duty of Assistance, in Philosophy Now, Oct. 2006.

U. S. Bishops. Economic Justice for All. Washington: NCCB, 1986.

Uchtitelle, L. S., "How to Define Poverty: Let us Count the Ways" in New York Times, Saturday, May 26, 2001.

Umez, B. N. Nigeria - Real Problems, Real Solutions. Enugu: Snaap Press, 2000.

Vanguard Newspaper, Sunday, 20 April, 2006. 